\subsection{Summary}

Studies of gradience in phonology using linguistic and metalinguistic data have revealed a much closer connection between phonological grammar and the mental lexicon. These new dimensions of phonological variation could not have been discovered without corpus methods and data from groups of participants in psycholinguistic experiments. While the range of patterns that have been studied is still quite limited, the presence of gradient phonological constraints demonstrates that phonological knowledge goes beyond a categorical symbolic representation of possible forms in a language. In order to accommodate the broader scope of phonological generalizations, models of grammar will have to become more like models of other cognitive domains, which have long recognized and debated the nature of frequency and similarity effects for mental representation and processing. The study of phonology may provide a unique contribution in addressing these more general questions in cognition for two reasons. The scope of phonological variability is bounded by relatively well-understood mechanisms of speech perception and speech production. Also, phonological categories and phonological patterns provide a sufficiently rich and intricate variety of alternatives that the full complexity of cognitive processes can be explored.

\section{Intermediate Syntactic Variants in a Dialect-Standard Speech Repertoire and Relative Acceptability}

LEONIE CORNIPS

\subsection{Introduction}

Non-standard varieties, such as dialects throughout Europe, which are under investigation challenge research about the phenomenon of micro-variation in two ways. ${ }^{1}$ Within the framework of generative grammar, the linguist studies the universal properties of the human language in order to find out the patterns, loci, and limits of syntactic variation. Language is viewed essentially as an abstraction, more specifically, as a psychological construct (I-language) that refers primarily to differences between individual grammars within a homogeneous speech environment, that is to say; without consideration of stylistic, geographic, and social variation. Given this objective, a suitable investigative tool is the use of intuitions or native-speaker introspection, an abstraction that is quite normal within the scientific enterprise: Frequently, however, there are no sufficiently detailed descriptions available of syntactic phenomena that are of theoretical interest for investigating micro-variation in and between closely related non-standard varieties in a large geographical area (cf. Barbiers et al. 2002). Subsequently, a complication emerges in that the linguist has to collect his own relevant data from speakers of local dialects who are non-linguists. The elicitation of speaker introspection often calls for a design of experiments in the form of acceptability judgements when the linguist has to elicit intuitions from these speakers (Cornips and Poletto 2005).

${ }^{1}$ I like to thank two anonymous reviewers for their valuable comments. Of course, all usual disclaimers apply. 
Moreover, the standard variety may strongly interfere with local dialect varieties in some parts of Europe so that there is no clear-cut distinction between the standard and the local dialect. In this contact setting-a so-called intermediate speech repertoire (cf. Auer 2000) - the speakers of local dialects may assess all possible syntactic variants, that is dialect, standard, and emerging intermediate variants to their local dialect. Subsequently, clear-cut judgements between the local dialect and the standard variety are not attainable at all. This is, among other factors, of crucial importance for understanding the phenomenon of gradedness in acceptability judgements.

This chapter is organized as follows. In the second part it is proposed that acceptability judgements do not offer a direct window into an individual's competence. The third part discusses an intermediate speech repertoire that is present in the province of Limburg in the Netherlands. In this repertoire some constructions are difficult to elicit. Finally, acceptability judgements that are given by local dialect speakers in the same area are discussed. Using data from reflexive impersonal passives, reflexive ergatives, and inalienable possession constructions, it is argued that the occurrence of intermediate variants and the variation at the level of the individual speaker is not brought about by specific task-effects but is due to the induced language contact effects between the standard variety and the local dialects.

5.2 Relative acceptability

Bard et al. (1996: 33) discuss the important three-way distinction among grammaticality, a characteristic of the linguistic stimulus itself, acceptability, a characteristic of the stimulus as perceived by a speaker, and an acceptability judgement which is the speaker's response to the linguists' enquiries. These authors note that relative grammaticality is an inherent feature of the grammar whereas relative acceptability reflects gradience in acceptability judgements. The former has a controversial status since it is not entirely clear how to deal with relative grammaticality in formal theory. According to Schütze, the best-known proponents of the view that grammaticality occurs on a continuum are Ross, Lakoff and their followers in the late 1960s and early 1970s (see Schütze 1996: 62, 63 for more detail).

With respect to acceptability judgements, every elicitation situation is artificial: the speaker is being asked for a sort of behaviour that, at least on the face of it, is entirely different from everyday conversation (cf. Schütze 1996: 3 ). Moreover, Chomsky (1986: 36) argues that: 'In general, informant judgments do not reflect the structure of the language directly; judgments of acceptability, for example, may fail to provide direct evidence as to grammatical status because of the intrusions of numerous other factors' (cf. Gervain 2002). 'The intrusion of numerous other factors' may lead to a crucial mismatch between the acceptability judgements of a construction and its use in everyday speech. One of these factors is that in giving acceptability judgements people tend to go by prescriptive grammar (what they learned at school, for instance) rather than by what they actually say (cf. Altenberg and Vago 2002). This is consistent with sociolinguistic research that prescriptive grammars usually equal standard varieties that are considered more 'correct' or have more prestige than the vernacular forms speakers actually use. Moreover, strong sociolinguistic evidence shows that a speaker may judge a certain form to be completely unacceptable but can, nevertheless, be recorded using it freely in everyday conversation (Labov 1972, 1994, 1996: 78). One way to diminish the prescriptive knowledge effect is to ask for indirect comparative acceptability judgements. Rather than eliciting direct intuitions by the formula: 'Do you judge $\mathrm{X}$ a grammatical/better sentence than Y?', speakers can be asked the more indirect: "Which variant $\mathrm{Y}$ or $\mathrm{X}$ do you consider to be the most or the least common one in your local dialect?' Relative judgements can be administered by asking the speakers to indicate how uncommon or how common (for example represented by the highest/lowest value on a several point scale, respectively) the variant is in their local dialect. Psychometric research shows that subjects are thus much more reliable on comparative, as opposed to independent ratings (cf. Schütze 1996: 79 and references cited there). These findings indicate that relative acceptability is an inevitable part of the speaker's judgements.

Relative acceptability is without doubt brought about by the complex relationship between I-language and E-language phenomena. The opposition between these two types of phenomena is not necessarily watertight as is often claimed in the literature. Muysken (2000: 41-3) argues that the cognitive abilities which shape the I-language determine the constraints on forms found in the E-language and that it is the norms created within E-language as a social construct that make the I-language coherent. One example of this complex relationship may be that in a large geographical area two or more dialects may share almost all of their grammar (more objective perspective) but are perceived as different language varieties by their speakers (more subjective perspective). This can be due to the fact that dialects may differ rather strongly in their vocalism and that non-linguists are very sensitive to the quality of vowels. The perceived differences between dialects may be associated with different identities and vice versa. Another consequence may be that speakers actually believe that the norm created within their speech community (E-language; more subjective perspective) reflects their grammar 
(I-language; more objective perspective). For example, in the Dutch Syntactic Atlas project (acronym SAND) we asked dialect speakers to 'translate' standard Dutch verbal clusters containing three verbs, as exemplified in (5.1), into their local dialect (cf. Cornips and Jongenburger 2001). ${ }^{2}$

(5.1) Ik weet dat Jan hard moet kunnen werken

I know that Jan hard must can work

Quite a number of speakers told us that their dialects are simpler or more informal than standard Dutch. Therefore, sentences such as (5.1) are judged as ungrammatical or less grammatical than sentences containing two-verb clusters. However, there is not one Dutch dialect attested that excludes construc tions as in (5.1). So, it is important to realize that the use of the dialect and the standard variety in a specific setting may be triggered by stylistic or socia factors (in a specific setting, with specific interlocutors) if these varietie constitute a continuum. This information minimizes the risk that we are obtain ing information about the prescriptive norms of the standard (or prestigious or formal) variety while our intention is rather to question speakers about their dialect (or vernacular non-standard) forms.

\subsection{The intermediate speech repertoire}

The so-called intermediate speech repertoire (cf. Auer 2000) as exemplified in the southeastern part of the Netherlands (province of Limburg) is presumably the most widespread in Europe today. In this repertoire, there is a structura or genetic relationship between the standard variety and the dialects (cf. Auer 2005). The influence of the standard variety on the dialects is quite manifest. There is no longer a clear-cut separation between the varieties, that is to say, speakers can change their way of speaking without a clear and abrupt point of transition between these varieties. This is of crucial importance to understanding relative acceptability.

In general, syntactic elicitation provides no difficulties if structures are grammatical in the standard variety and ungrammatical in the dialects (Cornips and Poletto 2005). The speakers usually refuse these constructions, either by providing a grammatical alternative or by simply not being able to translate the sentence and, hence, show non-response. For instance, in the local dialect of Heerlen (a city in the south of the province of Limburg in the Netherlands, see Figure 5.1) negation agreement in (5.2a) is ungrammatical.

2 More information about the SAND-project can be found at: http://www.meertens.nl/projecten/ sand/sandeng.html
The local dialect speaker easily provides an alternative, as shown in (5.2b) (taken from the Dutch Syntactic Atlas-project):

(5.2) Instruction: 'Translate into your local dialect'

a. Er wil niemand niet dansen

expl will no one not dance

'No one wants to dance.'/ 'Everyone wants to dance.'

Translation:

b. Gene wilt danse

no one wants dance

'No one wants to dance.'

Second, speakers may provide syntactic features that are obligatory in the local dialect even if the same phenomenon is banned from the standard variety. In this case speakers seem to be able to distinguish whether a given construction is grammatical without interference from prescriptive norms. In the dialect of Heerlen and standard Dutch, there is a very sharp contrast between the grammaticality of the impersonal passive with and without a reflexive, respectively. The local dialect speakers in Heerlen were asked whether they encounter the variant in (5.3a) in their local dialect. This variant is fully ungrammatical in the standard variety. The majority of the subjects ( 16 out of 24,67 per cent) provide an affirmative answer, which is confirmed by their translation, as exemplified in $(5.3 \mathrm{~b}):$

(5.3) Local dialect of Heerlen

Instruction: 'Do you encounter this variant'

Er in cich '

$\begin{array}{llll}\text { Er } & \text { wordt } & \text { zich } & \text { gewassen } \\ \text { there }_{\text {EXPL }} & \text { is } & \text { REFL } & \text { washed }\end{array}$

Answer: 'Yes' and translation

b. 't weëd zich gewessje

there EXPL $_{\text {is }}$ REFL washed

'One is washing himself'

Finally, in the case that the phenomenon is optional, speakers tend to reproduce the standard variety, because this is nonetheless grammatical in their dialect (Cornips and Poletto 2005). This issue is nicely illustrated by responses to constructions in which an aspectual reflexive zich (an optional element) is offered to the Limburg dialect speakers, as illustrated in (5.4) (cf. Cornips 1998):

${ }^{3}$ However, the plain impersonal passive is also grammatical in the local dialect of Heerlen. In tha case it has no reflexive interpretation: 'One is washing (clothes)? 
(5.4) d'r Jan had zich in twieë minute e beeke gedrònke the Jan had refl in two minutes a small beer drunk

The construction with the reflexive zich is fully ungrammatical in the standard variety but optional in the local dialect. The written questionnaire of the Dutch Syntactic Atlas project shows that in only two out of thirty-five possible locations in the province of Limburg and its immediate surroundings, an answer with the reflexive is given. Obviously, the interference with the standard variety is so strong that the reflexive is not presented in the answers. It seems that only a very good subject can provide optional structures or all the possibilities that come to his mind.

5.3.1 Heerlen Dutch as an emerging intermediate regional standard variety Without any doubt, every emerging intermediate speech repertoire is a result of an induced language contact situation and/or processes of standard-dialect and/or dialect-dialect convergence, that is to say, vertical and horizontal levelling, respectively (cf. Cornips and Corrigan 2005). The emergence of intermediate variants, which may result in a regional variety as a second standard in the area, is crucial to understanding the phenomenon of syntactic variation within the speech community and at the individua speaker level.

A good example of an intermediate variety due to language contact effects is Heerlen Dutch (Cornips 1998). Heerlen Dutch is a regional standard Dutch variety in the Netherlands. Heerlen is a town of 90,000 inhabitants, situated in Limburg, a province in the southeast of the Netherlands near the Belgian and German borders (see Figure 5.1).

As already discussed above, in the local dialect of Heerlen reflexives may occur in a much wider range of constructions than in standard Dutch. An example is the appearance of the reflexive zich in inchoative constructions. In standard Dutch (SD) the appearance of $z i c h$ in inchoative verb constructions is far from regular. Zich is required in (5.5a), is optional in (5.5b), and obligatorily absent in (5.5c) (cf. Everaert 1986: 83, SD = standard Dutch):

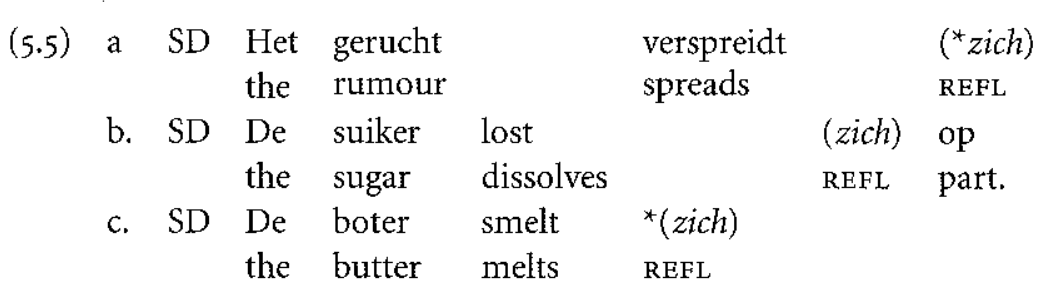

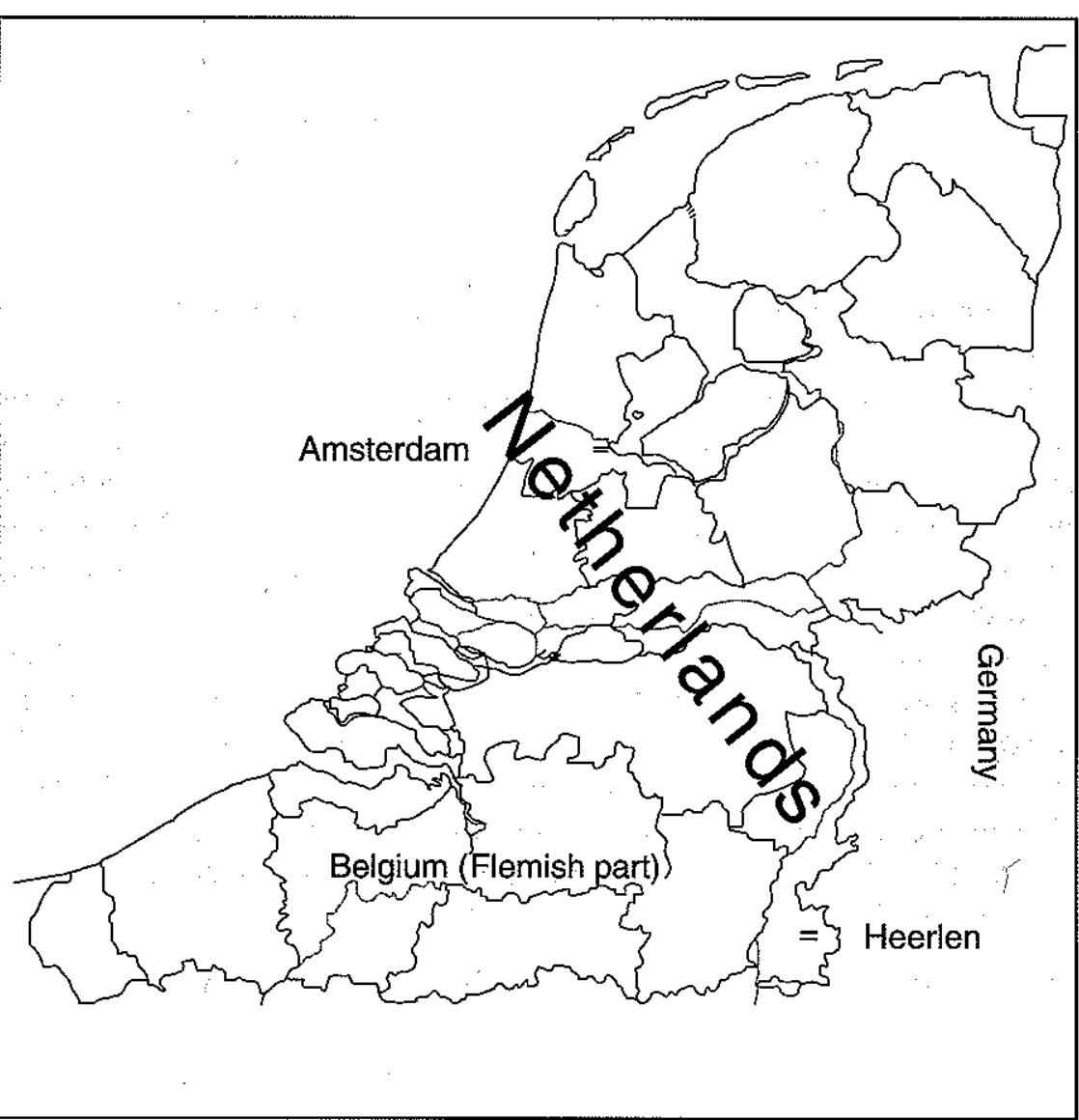

FIGURE 5.1. The location of Heerlen in the province of Limburg

In the local dialect of Heerlen, the reflexive zich has to be present in $(5.5 \mathrm{~b})$ and it may be present in $(5.5 \mathrm{c})$. Further, it also arises in some more inchoative constructions based on transitive verbs as veranderen 'change', krullen 'curl' and buigen 'bend'. All these inchoative constructions are fully ungrammatical with a reflexive in the standard variety. Heerlen Dutch, however, as a second standard variety in the area has regularized the presence of the reflexive throughout the whole verb class. It has an optional reflexive zich in the construction in $(5.5 \mathrm{c})$ and also in (5.6) which are ungrammatical in the local dialect (and in the standard variety) $(\mathrm{HD}=$ Heerlen Dutch):

${ }^{4}$ In Cornips and Hulk (1996), it is argued that the Heerlen Dutch constructions in (5.6) are ergative intransitive counterparts of transitive change of state verbs with a causer as external argument aspection 
(5.6) a. HD Dit vlees bederft zich

this meat spoils REFL

b. HD De jurk sleept zich over de vloer

the dress drags REFL over the floor

c. HD Het glas breekt zich

$$
\text { the glass breaks REFL }
$$

It is important to note that optionality arises as an induced contact outcome (see also later in Section 5.3.2).

Another example of an emerging variant in Heerlen Dutch concerns the socalled dative inalienable possession construction in which the referent of the dative object is the possessor of the inalienable body-part(s) denoted by the direct object. Importantly, all (old) monographs of the Heerlen dialect and written dialect literature (see Blancquaert et al. 1962; Jongeneel 1884; Kessel 1883) show that in the local dialect the DP referring to the body-part(s) such as handen 'hands', illustrated in (5.7), is headed by the definite determiner $d e$ 'the'. The possessive dative construction expressing inalienable possession is abundantly used in the eastern dialect varieties of Dutch, although extremely rare in standard Dutch (cf. Broekhuis and Cornips 1994; Cornips 1998). The inalienable possession construction, as far as possible, has an idiomatic reading in standard Dutch that is completely absent in this regional Dutch variety and in the dialects of Limburg (Hdial = Heerlen dialect):

$$
\begin{array}{ll}
\text { (5.7) Hdial } / \text { ? } * \mathrm{SD} & \text { Ik was Jan } n_{\text {dat }} / \text { hem }_{\text {dat. }} \text { de handen. } \\
& \text { I wash Jan/him the hands } \\
\text { 'I am washing Jan's/his hands.' }
\end{array}
$$

Hence, in the standard variety the inalienable possession relation must be expressed by means of a possessive pronoun, namely zijn 'his', as illustrated in (5.8). The construction in (5.8) is in turn rare in the local dialect of Heerlen

$$
\begin{array}{ll}
\text { (5.8) } \mathrm{SD} / \mathrm{P}^{*} \text { Hdial } & \text { Ik was zijn/Jans handen. } \\
& \text { I wash his/Jan's hands } \\
& \text { 'I am washing his/Jan's hands.' }
\end{array}
$$

Nowadays, Heerlen Dutch involves a large spectrum of intermediate lects varying between the local dialect and standard Dutch. As a result, in Heerlen Dutch we find both the inalienable dative construction in (5.7) and the possessive pronoun construction in (5.8). Thus, the syntactic variation within a regional variety as Heerlen Dutch corresponds to cross-linguistic differences between English and French, as in (5.9) and (5.10), respectively (Cornips 1998; Vergnaud and Zubizarreta 1992):
(5.9) a. Eng ${ }^{*}$ I am washing him dat $_{\text {d }}$ the hands.

b. Eng I am washing his hands.

(5.10) a. Fr *Je lave ses mains. (*inalienable reading)

b. Fr Je lui $i_{\text {dot }}$ lave les mains.

Moreover, in spontaneous speech data-although rarely-we even find intermediate forms such as the dative object in combination with the possessive pronoun, as in (5.11b) (cf. Cornips 1998, HD = Heerlen Dutch):

$\begin{array}{llll}\text { (5.11) a. HD } & \text { Ik was hem dat. de buik. } \\ & \text { I wash him the stomach } \\ \text { b. HD } & \text { Ik was hem dat. zijn buik. } \\ \text { intermediate form } & \text { I wash him his stomach } \\ \text { c. HD } & \text { Ik was } & \text { zijn buik. } \\ & \text { I wash } & \text { his stomach }\end{array}$

It is important to point out that this intermediate variant was already present in 1962 in the neighbouring community of Heerlen, that is Kerkrade. ${ }^{5}$ Obviously, the inalienable possessive construction is not a binary variable since it allows more than two variants, as illustrated in (5.11). Spontaneous speech data of intermediate variants is presented in (5.12) (see also (5.19) in Section 5.3.2 Cornips 1998). In (5.12) the inalienable possession relation is expressed both by means of a possessive dative je 'you' and by means of the possessive pronoun $j e$ 'your'. Note, however, that in all these examples the DP referring to an inalienable body-part is the complement of a PP and not a direct object: ${ }^{6}$.

(5.12) a. HD want ze zeuren $j e_{d a t}$ van alles naar $j e$ : because they nag you everything to your hoofd toe (19: Cor)

head PART

'They are nagging you about everything.

b. HD die had $j e_{\text {dat }}$ zo bij je neus staan they had you right away with your nose stand (35: dhr Berk)

They stand in front of you right away?

5 Blancquaert et al. (1962) denote the following translation in the local dialect of Kerkrade (in Dutch orthography):

(i) De schipper likte zich zijn lippen af

'The skipper licked his lips.'

6 The constructions in (5.12) with a PP are more accepted in standard Dutch than the double object constructions (see Broekhuis and Cornips 1997 for more details about this type of construction). 
In (5.13) the semi-copula krijgen 'get' cannot assign dative case to the possessor hij 'he' which is therefore nominative (cf. Broekhuis and Cornips 1994). However, the spontaneous speech data example in (5.13b) shows that the possessor is also realized by means of the reflexive zich, which is fully ungrammatical in the local dialect (like standard Dutch):

$$
\begin{aligned}
& \text { (5.13) a. HD Hij krijgt de handen vies } \\
& \text { he gets the hands dirty } \\
& \text { 'His hands are dirty.' } \\
& \text { b. HD Die heeft zich enorm op } z \text { 'n donder gekregen } \\
& \text { (33: dhr Quint) } \\
& \text { he has REFL enormously a beating got } \\
& \text { 'He gets hell.' }
\end{aligned}
$$

5.3.2 The lack of characteristic properties of the dative inalienable possession construction

Interestingly, it is not only the case that intermediate variants emerge in an intermediate speech repertoire but they also lack characteristic properties (Vergnaud and Zubizarreta 1992: 598) of the 'original' dative inalienable possession construction. Two important properties are the strictly distributive interpretation and grammatical number. The former refers to the presence of a plural possessor combined with a singular inalienable argument as in (5.14a). If that is the case, the referent of the inalienable argument is nevertheless interpreted as referring to more than one bodypart. The latter property refers to the fact that inalienable arguments are obligatorily singular when referring to body-parts of which the number per individual is limited to one such as 'head', regardless of whether they have a plural possessor or not. This is illustrated by the grammaticality contras between $(5.14 \mathrm{~b})$ and $(5.14 \mathrm{c})$ (note that there is no idiomatic reading involved):

(5.14) a. Ik was hun dat./3pl het hoofd (i.e. more 'heads' involved) I wash them the head 'I am washing their heads.'

b. ${ }^{*} \mathrm{Ik}$ was hun $_{\text {dat. } / 3 \mathrm{pl}}$ de hoofden $n_{\mathrm{pl}}$

I wash them the heads

'I am washing their heads.'

c. Ik was hun $n_{\text {dat. } / 3 \mathrm{pl}}$ de handen $\mathrm{pl}$

I wash them the hands

'I am washing (both) their hands.'
Let us now compare (5.14) with the spontaneous speech data example in (5.15) that occurs very infrequently in the corpus: ${ }^{7}$

(5.15) $\mathrm{HD} \mathrm{Ze} \mathrm{slaan}$ mekaar $_{\mathrm{pl}}$ niet meteen de koppen $_{\mathrm{pl}}$ in (5: Stef)

they hit each other not at once the heads in

'They don't hit each other immediately.'

Apparently, both a distributive interpretation and the property of grammatical number may no longer be characterizing properties of the intermediate forms in Heerlen Dutch, that is: the inalienable argument koppen 'heads' is plural although the number of the body-parts kop 'head' per individual is limited to one.

Finally, the dative construction cannot be modified by just any attributive adjective, whereas there is no such restriction in the possessive pronoun constructions, as exemplified in (5.16a) and (5.16b), respectively (Vergnaud and Zubizarreta 1992):

$$
\begin{aligned}
& \text { (5.16) a. HD 'Ik was hem } \mathrm{dat} \text { de vieze buik } \\
& \text { I wash him the dirty stomach } \\
& \text { 'I am washing his dirty stomach.' } \\
& \text { b. HD Ik was zijn vieze buik. } \\
& \text { I 'I wash his dirty stomach } \\
& \text { 'I am washing his dirty stomach.' }
\end{aligned}
$$

I asked speakers of Heerlen Dutch to tell a short story containing the elements vuil 'dirty' and handen 'hands'. In addition to (5.16b), they realize the intermediate variant in (5.17) which lacks, due to the presence of the possessive pronoun, any restriction on the presence of the adjective:

$$
\begin{aligned}
& \text { (5.17) } \mathrm{HD} \text { Hij wast hem } \mathrm{Hat}_{\text {ijn vuile handen. }} \\
& \mathrm{He} \text { washes him his dirty hands } \\
& \text { 'He is washing his dirty hands.' }
\end{aligned}
$$

Further, a major important aspect of emerging intermediate variants such as the ones described above is that optionality arises. Hence, a major characteristic of the dative inalienable possession construction is that the [spec TP]subject or the agent, cannot enter into a possessive relation with the direct

${ }^{7}$ One reviewer points out that the German counterpart of $(5.15)$ with a plural inalienable argument is grammatical, whereas the German counterpart of (5.14a) with a singular inalienable argument is Dutch. 
object (or prepositional complement), not even if the indirect object is absent, as illustrated in (5.18a). Thus, a possessive relation between the subject and the direct object can only be expressed indirectly, namely by inserting a dative NP or a reflexive zich, as in (5.18b), respectively (see Broekhuis and Cornips 1994; Vergnaud and Zubizarreta 1992)

$$
\begin{aligned}
& \begin{array}{lllllll}
\text { (5.18) } & \text { a. Hdial } / \mathrm{SD} & { }^{*} \mathrm{Hij}_{\mathrm{i}} & \text { wast } & & \text { de } & \text { handen } \\
& \text { b. Hdial } / \text { ? }{ }^{*} \mathrm{SD} & \mathrm{Hij}_{\mathrm{i}} & \text { wast } & \text { zich }_{\mathrm{i}} & \text { de } & \text { handen. }
\end{array} \\
& \text { he washes refl the hands } \\
& \text { 'He is washing his hands.' }
\end{aligned}
$$

However, in all the intermediate variants described so far in which the possessive relation is expressed by the possessive pronoun, the dative object or reflexive referring to a possessor is optional. Importantly, all constructions in (5.19), in contrast to the double object constructions, involve idiomatic readings: ${ }^{8}$

(5.19) a. HD ze zeuren $\left(j e_{d a t}\right)$ van alles naar je hoofd toe (19: Cor) they nag you everything to your head PART 'They are nagging you about everything.'

b. HD die had ( $\left(e_{\text {dat }}\right)$ zo bij je neus staan they had you right away with your nose stand (35: dhr Berk)

'They stand in front of you right away.'

c. HD Die heeft (zich) enorm op $z n$ donder gekregen (33: dhr Quint)

he has REFL enormously a beating got

'He gets hell.'

Taken together, these intermediate variants are of extreme importance with respect to the locus of syntactic variation, that is: whether the primitive of variation is located outside or inside the grammatical system. It becomes obvious that the facts in Heerlen Dutch indicate that syntactic variation can no longer exhaustively be described by binary settings or different values of a parameter (Cornips 1998). In an intermediate speech repertoire, this concept is a very problematic one and must be open to discussion. Different alternatives are possible but there are no satisfying answers yet. A more recent alternative is to argue that from a minimalist point of view, lexical elements

${ }^{8}$ It might be the case that, eventually, the optional dative object will disappear or that it will gain emphatic meaning. show minimal morphosyntactic differences, more specifically, whether they bear un- or interpretable features interacting with general principles. ${ }^{9}$ Another alternative is to place the notion of choice between syntactic variants into the grammatical system. Henry (1995) shows that imperatives in Belfast allow optional raising of the verb to $\mathrm{C}$ and inversion in embedded questions may or may not occur. She accounts for this optionality by arguing that a functional category such as $\mathrm{C}$ has both strong and weak features instead of different settings of a parameter. In sum, analyses differ with respect to the locus of syntactic variation (grammar versus lexicon) and whether individuals may have one or two (or more) grammars responsible for the various syntactic variants.

\subsection{Acceptability judgements in an intermediate speech repertoire}

The coming into existence of intermediate variants is of crucial importance for understanding the phenomena of relative acceptability and perhaps relative grammaticality. Hence, variationist studies have convincingly shown that individual speakers do not show all possible alternatives that exist at their level of their community (Henry 2002; Cornips 1998). So, the behaviour of individual speakers with respect to acceptability judgments cannot be interpreted without knowledge of the community pattern. An individual speaker thus has a passive knowledge of more possible syntactic alternatives than he actually uses due to the fact that these possible alternatives, that is standard, dialect, and emerging intermediate variants, can be heard daily in his community. The intermediate variants form a continuum with the standard and local dialect varieties. This continuum arises not only from a geographic perspective but also from a stylistic (for example the use of dialect and standard features in a more informal and formal setting, respectively) and social perspective (age, gender, ethnicity, levels of education, and occupation of the speaker) as well. I propose that a speaker may no longer be able to judge syntactic features as fully grammatical or ungrammatical. Instead, it is very likely that due to the effects of the standard-dialect $\mathrm{cr}$ stact situation the speaker can only make relative judgements by comparing those variants. Further, it might be the case that this gradience in acceptability judgements partly arises due to the relative

${ }^{9}$ However, even if the syntactic variants are analysed as coming into existence as a result of two competing grammars (cf. Kroch 1989), then some lexical elements must still bear un- and interpretable features as well in order to account for the syntactic alternatives. 
grammaticality of the intermediate variants in the community, namely the fact that intermediate variants no longer possess characterizing properties a discussed in 5.3.2.

In the former section, a regional standard variety was discussed. Let us now consider the local dialects in the same area. These dialects were investigated in the Dutch Syntactic Atlas project. The design of method ology in the Dutch Syntactic Atlas project consisted of two phases, written elicitation and oral elicitation. The oral acceptability judgement tasks were administered in dialect rather than in the standard variety or some regiolect, in order to avoid accommodation, that is adjustment from the dialect in the direction of the standard-like varieties (cf. Cornips and Poletto 2005). In the phase of oral elicitation, 250 locations were selected throughout the Netherlands. We had a major problem in doing the fieldwork since the large majority of the fieldworkers and Ph.D. students speak only the standard variety. It is for this reason that we had to ask for the assistance of another dialect speaker from the same community speaking the same variety in order to be able to interview the subject in his own dialect. The fieldworker (speaking only standard Dutch) trained a local dialect speaker as an 'assistant interviewer'. This 'assistant interviewer' was asked to translate a standard Dutch structured elicitation task into his or her local dialect. These translations were recorded. In a second session these recordings were played to the second local dialect speaker. In this session, the entire conversation was restricted to the two dialect speakers and the fieldworker did not interfere.

5.4.1 Oral elicitation: the local dialects

Two small case studies convincingly show how easily speakers switch between the (base) dialect and the standard variety in an oral task in the southern part of the province of Limburg where an intermediate speech repertoire exists. One of the locations involved in the project was Nieuwenhagen (Landgraaf) a very small 'rural' village in the environs of Heerlen. In the local dialect of Nieuwenhagen proper names are obligatorily preceded by the definite determiner $e t$ or der 'the' depending on whether the proper name refers to a female or male, respectively. The presence of the definite determiner preceding a proper name, as in (5.20), is fully ungrammatical in standard Dutch:

(5.20) et Marie/der Jan is krank DET Mary/DET Jan is il
The recording of the first session between the standard Dutch speaking fieldworker and the local 'assistant interviewer' translating standard Dutch into his own dialect shows that the definite article in his translation is absent: that is, the, proper names Wim and Els show up without it, as illustrated in (5.21). These sentences were elicited in order to investigate the order in the verbal cluster (right periphery):

(5.21) 1st session (dialect-standard)

$\varnothing$ Wim dach dat ich $\varnothing E l s$ han geprobeerd e kado te geve

Wim thought that I Els have tried a present to give

'Wim thought I tried to give a present to Els.'

In the same interview session, the 'assistant interviewer' shows in another sentence that he may or may not use the definite article resulting in der Wim and $\varnothing E l_{s}$ respectively in his local dialect. Note that the definite determiner precedes the subject DP whereas it is absent in front of the object DP:

(5.22) 1st session (dialect-standard)

Der Wim dach dat ich $\varnothing E l s$ e boek han will geve DET Wim thought that I Els a book have will give 'Wim thought I wanted to give a book to Els.'

In the second session, however, in which the 'assistant interviewer' exclusively interviews the other dialect speaker in the local dialect, the latter utters the definite article both with th $\approx$ subject and object DP as 'required':

(5.23) 2nd session (dialect-dialect)

Der Wim menet dat ich et Els e boek probeerd ha kado te geve.

'Wim thought I tried to give a book to Els.'

Other indications for easily switching between the base dialect and standard Dutch can be found in (5.24). The infinitival complementizer has the form om and voor in standard Dutch and the local dialect, respectively (see Cornips 1996 for more details). In the first session, the 'assistant interviewer' in interaction with the standard Dutch speaking fieldworker uses the standard Dutch complementizer om whereas in the second session the dialect speaker utters voor, as illustrated in (5.24a) and (5.24b), respectively. Moreover, note that in the first session the proper name Wendy lacks the definite article again whereas it is present in the second session, as presented in (5.24a) and (5.24b), respectively:

(5.24) a. $\varnothing W e n d y$ probeerdet $o m$ ginne pien te doe. 1st session (dialectstandard) 
b. Et Wendy hat geprobeerd voor ginne pien te doe. 2nd session (dialectdialect)

'Wendy tried not to hurt anyone.'

It is important to note that these functional elements were not explicitly mentioned to the dialect speakers as features we were interested in. From the above, it is obvious that in this linguistic repertoire, speakers can adjust to the standard variety (and surrounding varieties) without a noticeable effort. This might be due to the fact that speakers are sensitive to their (un)conscious awareness of social diagnosticity of syntactic features, namely that features belonging to the domain of standard Dutch are the prestige variants (Cornips 1996). It is for this reason that training interviewers who are native speakers of the local dialect is necessary although every design has to take into account that standard, non-standard, and intermediate variants represent the daily speech situation, that is: syntactic features from the local dialects and standard Dutch appear in a continuum and have become continuous (cf. Paolillo 1997).

The emergence of new intermediate syntactic variants, too, points towards a direction in which it is no longer possible to make a clear-cut distinction between the standard variety and the local dialects from a syntactic point of view. In contrast, as already noted in the introduction, the experiences during fieldwork are that the Limburgian speakers perceive the local dialect and the standard variety as two different varieties and associate them with different identities although they share almost all of their grammar.

5.4.2 Written and oral acceptability judgements in the local dialect

In this section, written acceptability judgements about the inalienable possession construction are discussed. The first step in the design of the Dutch Syntactic Atlas project was an extensive written questionnaire containing 424 questions (including sub-questions and remarks to be made by the respondents) that were sent out to 850 respondents and a number of additional informants in Belgium (Cornips and Jongenburger 2001). The grid of the written questionnaires of the Dutch Syntactic Atlas project contains, among others, ten neighbouring villages of Heerlen. In this questionnaire, local dialect speakers were offered the possessive pronoun construction, as in (5.9), repeated here for convenience as $(5.25)$ :

(5.25) instruction 'Translate into your local dialect'

Ik was zijn handen.

I wash his hands

'I am washing his hands.
Example (5.26) and Figure 5.2 (on page 102) reveal the translations of (5.25) into the local dialect:

(5.26) 'translations'

\begin{tabular}{|c|c|c|}
\hline & & \\
\hline \multirow{5}{*}{$\begin{array}{l}\text { a. standard variant } \\
\text { b. standard variant } \\
\text { c. standard variant } \\
\text { d. standard variant } \\
\text { e. standard variant }\end{array}$} & Beek & he hät zien hanj geweschen \\
\hline & Eijgelshoven & He had sieng heng gewesche \\
\hline & Maastricht & heer heet zien han gewasse \\
\hline & Vaals & Hae hat zieng heng jewaesje \\
\hline & Waubach & $\begin{array}{l}\text { Heë hat zieng heng gewessje } \\
\text { he has his hands washed }\end{array}$ \\
\hline f. intermediate varia & Eijgelshoven & Heë had zieg sieng heng gew \\
\hline g. & Valf & Hae haet zich zien heng gen \\
\hline & & $\begin{array}{l}\text { i hea hat ziech zien heng jewesch } \\
\text { he has REFL his hands washed }\end{array}$ \\
\hline i. $d$ & Simpelveld & hea hat zich de heng gewesche \\
\hline & Waubach & $\begin{array}{l}\text { Hea haa zich de heng gewèse } \\
\text { he has REFL the hands washed }\end{array}$ \\
\hline
\end{tabular}

To begin with, the responses show that standard variants, dialect variants, and intermediate variants are among the answers. Further, all deviations of the input, for example intermediate and dialect variants as in $(5.26 \mathrm{f,g}, \mathrm{h})$ and $(5.26 \mathrm{i}, \mathrm{j})$ respectively, provide strong evidence that these variants are in the grammar of the speaker (Carden 1976). Moreover, variation arises within a local dialect, as is the case in the spontaneous speech data of Heerlen Dutch, which is a regional standard variety. Thus, two respondents in the location of Eijgelshoven and Waubach reveal different responses. The former displays both the standard and the intermediate variant in (5.26b), and (5.26f), respectively, whereas the latter yields the standard and the dialect variant in (5.26e) and (5.26j), respectively. Finally, the majority of the respondents copy the standard Dutch variant into their local dialect, as illustrated in $(5.26 \mathrm{a}-\mathrm{e}){ }^{10}$ In order to control for this task effect, we also administered this type of construction in the oral acceptability task (see below).

Taken together, the translations provide evidence that. (a) the standard variety strongly interferes with the local dialect variety, (b) intermediate variants arise, and (c) in this part of the province of Limburg syntactic features from the local dialects and standard Dutch exist in a continuum both in a regional standard variety and in the local dialects (see also (5.11)).

10 Maastricht, in the western part of Limburg, denoted the standard variant in 1962 (cf. Blancquaert possessive construction is more spoken in the eastern part of Limburg, i.e. Heerlen and surroundings. 


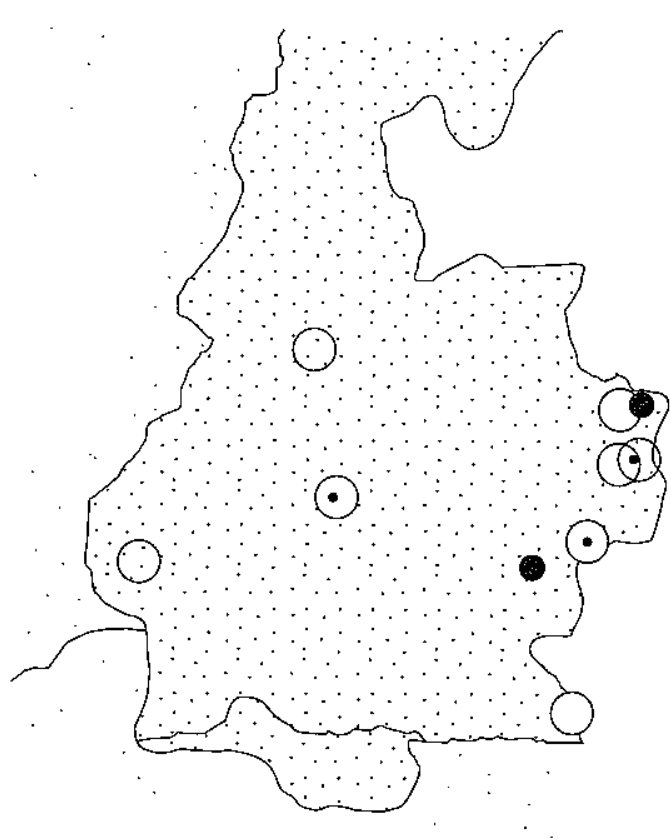

Possessive pronoun

(5)

- Intermediate forms

(3)

dative inalienable possession (2)

FIGURE 5.2. Possible inalienable possession constructions as revealed by the responses to the written questionnaire in ten surrounding locations of Heerlen

Similar to the written translation task, the standard Dutch possessive pronoun construction in (5.25) above was offered in the oral elicitation task, which was the second step in the Dutch Syntactic Atlas project. The location in the neighbouring villages of Heerlen where oral fieldwork was conducted are presented in Figure 5.3.

In the first section, that is the standard-dialect interaction (see 5.3.2) the assistant interviewers have been asked to translate (5.25) into their local dialect. Only 4 out of 12 respondents (33 per cent) immediately translate 5.25) into the dialect variant which is the dative inalienable possession construction. On the other hand, the majority of the assistant interviewers (8 out of 12,67 per cent) just copy the possessive pronoun construction into their local dialect. Hence, these respondents show interference from the

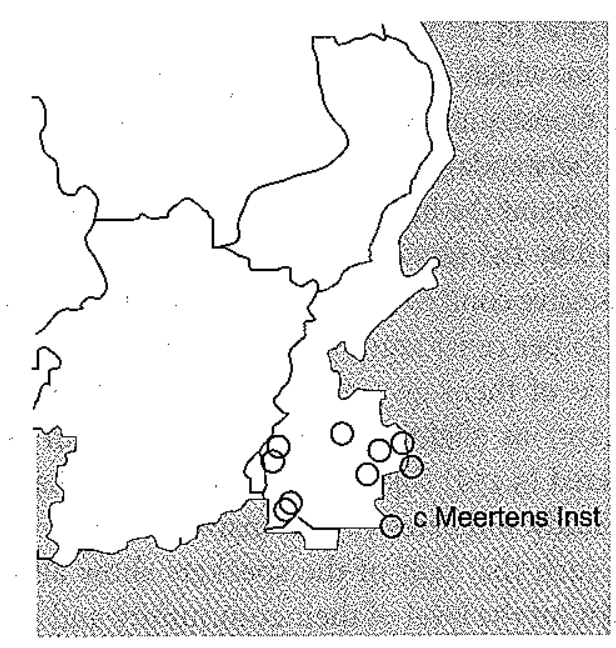

FIGURE 5.3. Grid of the oral interviews in Heerlen and neighbouring locations standard variety in shifting towards the more prestigious variety in their response, as is the case in the written elicitation task.

What is more, the majority of the respondents ( 6 out of 8,75 per cent) reveals an implicational pattern revealing that they copy the standard Dutch variant in the first session (dialect-standard repertoire) whereas they use the intermediate or the local dialect variant in the second session which is the dialect-dialect repertoire, as illustrated in (5.27).

(5.27) Location of Vaals:

Assistant interviewer:

a. Oversetz: 'Hij heeft zijn handen gewassen.' Instruction:

'Translate'

he has his hands washed

b. 1st session; 'Her had zien heng gewasse' standard-dialect he has his hands washed

c. 2nd session: 'Her had sich sien heng

dialect-dialect he has REFL his hands Assistant interviewer:

d. 'Komt disse

Her had zich de heng

gewasse

satz ook veur?'

'Do you also

$\mathrm{He}$ has RepL the hands

gewasse.

encounter

this variant?'

e. Answer: 
Again, the interaction in (5.27) reveals that the speech repertoire in Limburg is a continuous one in which the distinction between standard and dialect varieties is blurred. Consequently, the dialect speaker judges all possible variants, that is to say, the standard possessive pronoun $(5.27 \mathrm{~b})$, the dialect dative construction $(5.27 \mathrm{~d}, \mathrm{e})$, and the intermediate variant $(5.27 \mathrm{c})$ as acceptable. More evidence is presented by the fact that 9 out of 12 speakers ( 75 per cent) accept both the dative possessive construction and the intermediate form. Strikingly, 6 out of 12 speakers (50 per cent) argue that all forms in (5.27) are acceptable in the local dialect. Two of them give relative judgements without being asked: one considered $(5.27 \mathrm{c})$ as slightly more acceptable than $(5.27 \mathrm{~d})$, the other speaker just considered (5.27d) slightly more acceptable than $(5.27 \mathrm{c})$

This small case study indicates (a) extensive variation at the level of the individual speaker such that half of the speakers show all possible syntactic alternatives that exist on the level of their community and (b) the existence of intermediate variants to such an extent that it blurs the distinction between the local dialect and the standard variety. This result is attested in spontaneous speech, and in both the written and oral elicitation data, so we can exclude the possibility that it is primarily due to task effects. In this intermediate speech repertoire the occurrence of intermediate variants is inevitable in the process of vertical standard-dialect and horizontal dialect-dialect convergence. These findings put a question mark on the central sociolinguistic proposal that only phonology is a marker of local identity whereas syntax is a marker of cohesion in large geographical areas. Further, syntactic elicitation shows that speakers of local dialects are no longer able to refuse syntactic variants as fully ungrammatical even if (a) these concern emerging intermediate variants and (b) they did not originally belong to their local dialect variety. Consequently, relative acceptability is the result.

\subsection{Conclusion}

In this paper, I have discussed a so-called intermediate speech repertoire, that results from a contact situation between standard Dutch, a regional Dutch variety (Heerlen Dutch), and local dialects in the southern part of the province of Limburg in the south of the Netherlands. This speech repertoire reveals syntactic differences along a continuum to such an extent that it blurs the distinction between the local dialect and the standard variety. It is demonstrated that in this speech repertoire clear-cut judgements are not attainable at all. Using case studies, it has been shown that speakers in this area are not able to judge syntactic features as fully grammatical or ungrammatical. Instead, all variants heard in the community, for example standard, dialect, and intermediate variants are considered as acceptable. Moreover, it may be argued that in this speech repertoire dialect and standard varieties form a continuum also beyond the geographic level, that is to say, a continuum from a stylistic and social variation perspective. Subsequently, the findings in these case studies can be generalized beyond geographical variation. Moreover, these case studies show that syntax may also be a marker of local identity 